\title{
Widening the Lens on Language Learning: Language Creation in Deaf Children and Adults in Nicaragua
}

\section{Commentary on Senghas}

Susan Goldin-Meadow

University of Chicago, Chicago., Ill., USA

\author{
Key Words \\ Gesture $\cdot$ Homesign $\cdot$ Resilient and fragile properties of language $\cdot$ Sign language
}

Children around the globe learn language under a wide range of circumstances, and they do it remarkably well. The premise of this special issue is that we can glean insights about language learning from children who learn language under special circumstances that we cannot gain from children learning language under typical circumstances. Indeed, much can be learned about the child's contributions to language learning by varying either the learner or the learning environment [e.g., Gleitman \& Newport, 1996]. Because we cannot experimentally vary the circumstances under which children learn language, we need to take advantage of naturally occurring variations - children learning language under special circumstances.

As an example of a naturally occurring variation in the learner, some children have a specific impairment that seems to affect only their ability to learn language. Studying them can provide insight into characteristics of the learner that matter for language learning [Hsu \& Bishop, this issue]. As an example of a naturally occurring variation in the learning environment, some children are exposed not to 1 language but to 2 . Studying them can provide insight into characteristics of linguistic input that impact language learning [Sebastian-Gallés, this issue]. To the extent that a particular variation has an impact on what the child learns, we can conclude that the characteristic either of the learner or of the learning environment plays a role in how children learn language. Conversely, to the extent that a variation leaves language learning unchanged from the typical case, we know that language learning is resilient across that variation [Goldin-Meadow, 2003].

\section{KARGER}

Fax +41613061234

E-Mail karger@karger.ch

www.karger.com (c) 2010 S. Karger AG, Basel

Accessible online at: www.karger.com/hde
Susan Goldin-Meadow

Department of Psychology, University of Chicago 5730 South Woodlawn Avenue, Chicago, IL 60637 (USA) Tel. +1 773702 2585, Fax +1 7737020320

E-Mailsgm@uchicago.edu 


\section{Language Learning and Language Creation in Deaf Individuals}

Language learning in deaf children illustrates both types of variations. Children whose profound hearing losses prevent them from apprehending speech are different kinds of learners from children whose hearing is intact - they cannot easily process input by mouth and ear but have no difficulty processing input by hand and eye. And, indeed, the striking finding is that when deaf children are exposed to input that they can process - input from a conventional sign language - they acquire that language as naturally as hearing children acquiring a spoken language from their hearing parents and, importantly, they follow the same trajectory of linguistic milestones [Lillo-Martin, 1990; Newport \& Meier, 1985].

The natural language learning environment for a profoundly deaf child, then, is a signing environment. But $90 \%$ of deaf children are born to hearing parents and thus are not exposed to sign language at their mother's knee. Consequently, most deaf children are acquiring language in learning environments that are far from typical. Indeed, the deaf individuals studied by Senghas [this issue] find themselves in an even more extreme situation - there is no sign language in the community to be exposed to. What Senghas shows us is that, under these circumstances, a language can develop. The language, Nicaraguan Sign Language (NSL), was created by deaf individuals brought together for the first time in the late 1970s (first-generation cohort), who, in turn, passed the language on to the next generation of deaf individuals (second-generation cohort). Contrasting the linguistic structures found in the language systems used by these 2 cohorts provides us with insight into the role that a new generation of learners can play in shaping a language. Senghas [2003] has also shown that the innovations introduced into NSL by the second cohort came primarily from deaf individuals who entered the deaf community as children, rather than as adults. Thus, although the initial language formation was likely to have been done by a mixed community of children, adolescents, and adults, subsequent changes were initiated by young learners rather than old.

The particular grammatical device that Senghas [this issue] focuses on is a contrastive use of spatial modulations on signs. Spatial modulations can be used to indicate the roles that different participants play in an event, a grammatical device found in many established sign languages [e.g., Klima \& Bellugi, 1979; Meier, 1987; Padden, 1988]. For example, when describing a woman hitting a man, the signer moves the hit sign from a location representing the woman (the subject) to a location representing the man (the object). In this way, spatial modulations link the referents woman and man to the hitter subject role and the hittee object role, respectively. But spatial modulations can also be used to indicate the spatial locations and orientations of referents. For example, when indicating that a woman is standing to the left of a man, the signer can place the sign for woman to the left of the sign for man. The question Senghas addresses is whether the more abstract use of spatial modulation to indicate grammatical roles grows out of the more concrete use of spatial modulation to indicate the spatial location of objects. If so, we would expect that the grammatical role function would appear in a language only if the language already has the location function. But the patterns found in the NSL cohorts do not support this expectation.

In order for a spatial modulation to indicate who does what to whom, signers must consistently use the same layout across sentences. For example, if the woman 
is placed on the left of the signing space in sentence 1 but on the right in sentence 2 , when the signer then moves the hit sign from the right to the left, the communication partner cannot use the signer's spatial layout to figure out who the doer is. Senghas [this issue] elicited sign sentences from the participants in her studies by showing them video clips of the same actors performing a variety of activities. There are 2 ways in which referents can be linked to locations in the signing space: (a) the signer can rotate her own perspective to match the perspective of the actors in the video (in this case, the signer's left is mapped to the actor's left); (b) the signer can mirror the layout on the video screen (that is, the signer's left is mapped to the actor's right), an unrotated perspective. Cohort 2 consistently uses a rotated perspective across sentences when marking who does what to whom. Cohort 1 does not use this perspective reliably. At times, individuals in cohort 1 use a rotated perspective to mark grammatical roles, while at other times, they use an unrotated perspective. Interestingly, neither cohort is consistent when using spatial modulation to indicate the spatial location of objects - individual signers in both cohorts at times use the rotated perspective and at other times the unrotated perspective. Thus, the second cohort could not have figured out how to use space to represent grammatical roles by generalizing from the way they use space to represent space, as the 2 processes do not follow the same patterns in their language. As Senghas notes, either the processes were separate from the start, or they diverged at some point in development.

Senghas' careful look at how spatial modulation works in the first and second cohorts of NSL has widened the lens not only on language learning, but also on language itself. The findings suggest that passing a language through a new generation of learners can lead to reorganization of that language, bringing it closer to linguistic structures typically found in older, more established languages. Learners in the first and second cohorts of NSL presumably all came to language learning with comparable skills and biases. The differences in the languages they eventually came to use must reflect the fact that their skills and biases were applied to different inputs. Cohort 2 applied its skills to the language developed by cohort 1 . But what was the input that led to the language formed by cohort 1 ? In order to fully understand the language creation process that Senghas describes, we need to know more about its initial steps.

\section{Homesign - Input to the First Cohort of NSL}

The deaf children and adolescents present in the earliest stages of NSL had not previously been exposed to, nor acquired, a spoken, written, or signed language. However, like deaf individuals in similar situations in other cultures [Goldin-Meadow, 2003], they had likely invented gestures to communicate with their hearing family members, called homesigns. Thus, what began as a collection of individual homesign systems eventually converged onto a single, common system that has become NSL. There is consequently a link between homesign systems in Nicaragua and NSL [Coppola \& Senghas, 2010], comparable to the link found between homesign systems and older sign languages (e.g., American Sign Language) [Supalla, 2008]. We can therefore view homesign systems as the first steps in the evolution of sign language structure. 
Although little is known about the homesigns used by children (as opposed to adults) in Nicaragua, we know a great deal about child homesign in other countries (e.g., United States, China, Turkey). The child homesigners who have been extensively studied [for a review, see Goldin-Meadow, 2003] were congenitally deaf children who had not succeeded in mastering spoken language, often despite intensive oral education, nor had they been exposed to a conventional sign language by their hearing parents. Despite their lack of a usable model of conventional language, these homesigners were found to communicate using gesture systems characterized by many of the properties found in natural languages.

For example, homesigners' gestures form a lexicon. These lexical items are composed of parts, akin to a morphological system [Goldin-Meadow, Mylander, \& Butcher, 1995; Goldin-Meadow, Mylander, \& Franklin, 2007]. Moreover, the lexical items combine to form structured sentences, akin to a syntactic system [Feldman, Goldin-Meadow, \& Gleitman, 1978; Goldin-Meadow \& Mylander, 1984, 1998; Goldin-Meadow, Özyürek, Sancar, \& Mylander, 2009]. In addition, child homesign contains lexical markers that modulate the meanings of sentences (negation and questions) [Franklin, Giannakidou, \& Goldin-Meadow, in press], as well as grammatical categories (nouns and verbs) [Goldin-Meadow, Butcher, Mylander, \& Dodge, 1994] and the hierarchical structure that results from elaborating an argument in a sentence (using a noun phrase rather than a bare noun) [Hunsicker \& Goldin-Meadow, submitted] or adding a second proposition to a sentence (using a complex sentence) [Goldin-Meadow, 1982]. Finally, child homesign is used not only to make requests of others, but also to comment on the present and non-present [Butcher, Mylander, \& Goldin-Meadow, 1991; Morford \& Goldin-Meadow, 1997]; to make generic statements about classes of objects [Goldin-Meadow, Gelman, \& Mylander, 2005]; to tell stories about real and imagined events [Morford, 1995; Phillips, Goldin-Meadow, \& Miller, 2001]; to talk to oneself [Goldin-Meadow, 2003], and to talk about language [Goldin-Meadow, 1993] - that is, to serve typical functions that all languages serve, signed or spoken.

In countries like the United States, China and Turkey, homesigners are likely to learn a conventional sign language at some later point in their lives, often around adolescence. However, in Nicaragua, many homesigners continue to use the gesture systems they create as children as their sole means of communication. Analyses of adult homesign in Nicaragua have uncovered linguistic structures that go beyond the structures found thus far in child homesign: the grammatical category Subject [Coppola \& Newport, 2005]; pointing devices representing locations versus nominals [Coppola \& Senghas, 2010]; morphophonological finger complexity patterns [Brentari, Coppola, Mazzoni, \& Goldin-Meadow, 2010], and morphological devices that mark number [Coppola, Spaepen, \& Goldin-Meadow, in press]. By contrasting the linguistic systems constructed by child and adult homesigners, we can see the impact that growing older has on language.

In addition, by contrasting the linguistic systems constructed by adult homesigners in Nicaragua with the structures used by the first cohort of NSL signers, we can see the impact that a community of users has on language. Having a group with whom they could communicate meant that the first cohort of signers were both producers and receivers of their linguistic system, a circumstance that could lead to a system with greater systematicity - but perhaps less complexity, as the group may need to adjust to the lowest common denominator. 
Finally, by contrasting the linguistic systems developed by cohorts 1 and 2 (as Senghas [this issue] does), we can see the impact that passing a language through a new generation of learners has on language. Once learners are exposed to a system that has linguistic structure (i.e., cohort 2 and beyond), the processes of language change may be identical to the processes studied in historical linguistics. One interesting question is whether the changes seen in NSL in its earliest stages are of the same type and magnitude as the changes that occur in mature languages over historical time.

\section{Co-Speech Gesture - Input to Homesign}

A defining feature of homesign is that it is not shared in the way that conventional communication systems are. Deaf homesigners produce gestures to communicate with the hearing individuals in their homes. But the hearing individuals, particularly hearing parents in the United States, China, and Turkey who are committed to teaching their children to talk, use speech back. Although this speech is often accompanied by gesture [Flaherty \& Goldin-Meadow, 2010], the gestures must form an integrated system with speech [McNeill, 1992] and thus are not free to take on properties of the deaf child's gestures. As a result, although the parents respond to their deaf child's gestures, they do not adopt the gestures themselves (nor do they typically acknowledge that the child even uses gesture to communicate). The parents produce co-speech gestures, not homesigns.

Not surprisingly, then, the structures found in child homesign cannot be traced back to the spontaneous gestures that hearing parents produce while talking to their children [Goldin-Meadow \& Mylander, 1983, 1984; Goldin-Meadow et al., 1994, 1995]. The homesigners see the global and unsegmented gestures that their parents produce [McNeill, 1992]. But when gesturing themselves, homesigners generate gestures that are discrete, segmented forms joined together into structured strings. The gestures that hearing individuals produce when they talk therefore do not provide a model for the linguistic structures found in homesign. Nevertheless, co-speech gestures could provide the raw materials for the linguistic constructions that homesigners build [see, for example, Goldin-Meadow et al., 2007] and, as such, contribute to our picture of this emerging language [Senghas, Kita, \& Özyürek, 2004]. Moreover, the disparity between co-speech gesture and homesign has important implications for language learning. To the extent that the properties of homesign differ from the properties of co-speech gesture, the deaf children themselves must be imposing these particular structural properties on their communication systems. It is an intriguing, but as yet unanswered, question as to where the tendency to impose structure on homesign comes from.

Co-speech gestures do not assume the linguistic properties found in homesign. But what would happen if we were to ask hearing speakers to abandon speech and create a manual communication system on-the-spot? Would that system contain the linguistic properties found in homesign? Examining the gestures that hearing speakers produce when they are requested to communicate without speech allows us to explore the robustness of linguistic patterns constructed on-line in the manual modality. Interestingly, hearing gesturers studied under these experimental circumstances are able to construct some properties of language with their 
hands; for example, they use the order of gestures to indicate who does what to whom [Gershkoff-Stowe \& Goldin-Meadow, 2002; Goldin-Meadow, McNeill, \& Singleton, 1996]. However, they do not seem to be able to construct other linguistic properties with their hands; for example, they do not use consistent form-meaning pairings akin to morphemes found in conventional sign languages and homesign [Singleton, Morford, \& Goldin-Meadow, 1993]; they do not use finger complexity patterns found in conventional sign languages and homesign [Brentari et al., in press]; they do not string together segmented gestures for manner and path, the form found in conventional sign languages and homesign, and instead conflate manner and path into a single gesture (Özyürek, Furman, Kita, Sancar, \& GoldinMeadow, submitted).

Remarkably, when hearing speakers of 4 different languages (English, Spanish, Chinese, Turkish) are asked to describe animated events using their hands and no speech, they abandon the order typical of their respective languages and produce gestures that all conform to the same order: Actor-Patient-Act (e.g., captain-pailswings) [Goldin-Meadow, So, Özyürek, \& Mylander, 2008]. This order is also found when hearing speakers of the 4 languages perform a non-communicative transparency-stacking task; is consistent with the orders found in homesigners' 2-sign sentences across a variety of cultures; and is identical to the order found in a newly emerging sign language in Israel [Sandler, Meier, Padden, \& Aronoff, 2005]. Recent work on English, Turkish, and Italian speakers has replicated the Actor-Patient-Act order in hearing gesturers, but finds that gesturers move away from this order when given a lexicon (either spoken or manual) [Hall, Mayberry, \& Ferreira, 2010]; when asked to describe reversible events involving 2 animates (girl pulled man) [Meir, Lifshitz, Ilkbasaran, \& Padden, 2010], or when asked to describe more complex events (man tells child that girl catches fish) [Langus \& Nespor, 2010]. NSL signers have an established lexicon and they routinely communicate about complex events. Furthermore, adult Nicaraguan homesigners are likely to communicate about more complex events, and are more likely to have an acknowledged lexicon that they share with their adult communication partners, than child Nicaraguan homesigners. Thus, we might expect differences in the sign orders used by each of the groups in Nicaragua, particularly in relation to how spatial modulation is used to mark who does what to whom.

\section{Widening the Lens to Include Language Creation}

Senghas' [this issue] study is as much about language as it is about language learners. The unique circumstances in Nicaragua allow us to watch language as it grows. Previous work [e.g., Goldin-Meadow, 2003] has shown that we can discover the skills children bring to language learning by observing deaf children who communicate with their hearing parents using only gesture, that is, using homesigns. These homesigns contain many, but not all, of the properties found in natural languages. The circumstances in Nicaragua permit us to go beyond uncovering skills the child brings to language learning to gain insight into where those skills fall short; that is, to discover which properties of language are so fragile that they cannot be developed by a child lacking access to a conventional language model. By comparing current day child homesigners in Nicaragua with 
groups whose circumstances have allowed them to go beyond child homesign, we can determine which conditions foster the development of these relatively fragile linguistic structures. (1) We can observe changes made to the system when it remains the homesigner's sole means of communication into adulthood. Studying adult homesigners allows us to explore the impact that cognitive and social maturity has on linguistic structure. (2) We can observe changes made to the system when it becomes a community-wide language as homesigners come together for the first time. Studying the signers who originated NSL allows us to explore the impact that a community in which signers not only produce but also receive their communication has on linguistic structure. (3) We can observe changes made to the system when it is passed through subsequent generations of learners. Studying subsequent generations of NSL signers allows us to explore the impact that passing a newly birthed language through new generations of learners has on linguistic structure. (4) Finally, as a backdrop, we can study the gestures that hearing speakers in Nicaragua produce, with speech and without it, to better understand the raw materials out of which these newly emerging linguistic systems have risen.

By widening the lens on language learning to include language creation, we gain insight into the factors that have shaped language and its fit to language learners.

\section{Acknowledgement}

This research was supported by R01DC00491 from the National Institute of Deafness and Other Communicative Disorders.

\section{References}

Brentari, D., Coppola, M., Mazzoni, L., \& Goldin-Meadow, S. (in press). When does a system become phonological? Handshape production in gesturers, signers, and homesigners. Natural Language and Linguistic Theory.

Butcher, C., Mylander, C., \& Goldin-Meadow, S. (1991). Displaced communication in a self-styled gesture system: Pointing at the non-present. Cognitive Development, 6, 315-342.

Coppola, M., \& Newport, E. (2005). Grammatical Subjects in homesign: Abstract linguistic structure in adult primary gesture systems without linguistic input. Proceedings of the National Academy of Sciences, 102, 19249-19253.

Coppola, M., \& Senghas, A. (2010). The emergence of deixis in Nicaraguan signing. In D. Brentari (Ed.), Sign languages: A Cambridge language survey (pp. 543-569). Cambridge: Cambridge University Press.

Coppola, M., Spaepen, E., \& Goldin-Meadow, S. (submitted). Communicating about number without a language model: Linguistic devices for number are robust.

Feldman, H., Goldin-Meadow, S., \& Gleitman, L. (1978). Beyond Herodotus: The creation of language by linguistically deprived deaf children. In A. Lock (Ed.), Action, symbol, and gesture: The emergence of language. New York: Academic Press.

Flaherty, M., \& Goldin-Meadow, S. (2010). Does input matter? Gesture and homesign in Nicaragua, China, Turkey, and the USA. In A.D.M. Smith, M. Schouwstra, B. de Boer, \& K. Smith, (Eds.), Proceedings of the Eighth Evolution of Language Conference (pp. 403-404). Singapore: World Scientific Publishing Co.

Franklin, A., Giannakidou, A., \& Goldin-Meadow, S. (in press). Negation, questions, and structure building in a homesign system. Cognition.

Gershkoff-Stowe, L., \& Goldin-Meadow, S. (2002). Is there a natural order for expressing semantic relations? Cognitive Psychology, 45, 375-412. 
Gleitman, L., \& Newport, E. (1996). Universals of language learning. In L. Gleitman \& M. Liberman (Eds.), Invitation to cognitive science. Vol. 1: Language. Cambridge: MIT Press.

Goldin-Meadow, S. (1982). The resilience of recursion: A study of a communication system developed without a conventional language model. In E. Wanner \& L.R. Gleitman (Eds.), Language acquisition: The state of the art (pp. 51-77). New York: Cambridge University Press.

Goldin-Meadow, S. (1993). When does gesture become language? A study of gesture used as a primary communication system by deaf children of hearing parents. In K.R. Gibson \& T. Ingold (Eds.), Tools, language and cognition in human evolution (pp. 63-85). New York: Cambridge University Press.

Goldin-Meadow, S. (2003). The resilience of language. New York: Psychology Press.

Goldin-Meadow, S., Butcher, C., Mylander, C. \& Dodge, M. (1994). Nouns and verbs in a self-styled gesture system: What's in a name? Cognitive Psychology, 27, 259-319.

Goldin-Meadow, S., Gelman, S., \& Mylander, C. (2005). Expressing generic concepts with and without a language model. Cognition, 96, 109-126.

Goldin-Meadow, S., McNeill, D., \& Singleton, J. (1996). Silence is liberating: Removing the handcuffs on grammatical expression in the manual modality. Psychological Review, 103, 34-55.

Goldin-Meadow, S., \& Mylander, C. (1983). Gestural communication in deaf children: The non-effects of parental input on language development. Science, 221, 372-374.

Goldin-Meadow, S., \& Mylander, C. (1984). Gestural communication in deaf children: The effects and non-effects of parental input on early language development. Monographs of the Society for Research in Child Development, 49, 1-121.

Goldin-Meadow, S., \& Mylander, C. (1998). Spontaneous sign systems created by deaf children in two cultures. Nature, 91, 279-281.

Goldin-Meadow, S., Mylander, C., \& Butcher, C. (1995). The resilience of combinatorial structure at the word level: Morphology in self-styled gesture systems. Cognition, 56, 195-262.

Goldin-Meadow, S., Mylander, C., \& Franklin, A. (2007). How children make language out of gesture: Morphological structure in gesture systems developed by American and Chinese deaf children. Cognitive Psychology, 55, 87-135.

Goldin-Meadow, S., Özyürek, A., Sancar, B., \& Mylander, C. (2009). Making language around the globe: A cross-linguistic study of homesign in the United States, China, and Turkey. In J. Guo, E. Lieven, N. Budwig \& S. Ervin-Tripp (Eds.), Crosslinguistic approaches to the psychology of language: Research in the tradition of Dan Isaac Slobin (pp. 27-39). New York: Taylor \& Francis.

Goldin-Meadow, S., So, W.-C., Özyürek, A., \& Mylander, C. (2008). The natural order of events: How speakers of different languages represent events nonverbally. Proceedings of the National Academy of Sciences, 105, 9163-9168.

Hall, M., Mayberry, R., \& Ferreira, V. (2010). Communication systems shape the natural order of events: Competing biases from grammar and pantomime. Abstracts of the 4th conference of the International Society for Gesture Studies, Frankfurt.

Hunsicker, D., \& Goldin-Meadow, S. (submitted). Hierarchical structure in a self-created communication system: Are there noun phrases in homesign?

Klima, E., \& Bellugi, U. (1979). The signs of language. Cambridge: Harvard University Press.

Langus, A., \& Nespor, M. (2010). Cognitive systems struggling for word order. Cognitive Psychology, 60, 291-318.

Lillo-Martin, D. (1999). Modality effects and modularity in language acquisition: The acquisition of American Sign Language. In W.C. Ritchie \& T.K. Bhatia (Eds.), The handbook of child language acquisition (pp. 531-567). New York: Academic Press.

McNeill, D. (1992). Hand and mind. Chicago: University of Chicago Press.

Meier, R.P. (1987). Elicited imitation of verb agreement in American Sign Language: Iconically or morphologically determined? Journal of Memory and Language, 26, 362-376.

Meir, I., Lifshitz, A., Ilkbasaran, D., \& Padden, C. (2010). The interaction of animacy and word order in human languages: A study of strategies in a novel communication task. In A.D.M. Smith, M. Schouwstra, B. de Boer, \& K. Smith (Eds.), Proceedings of the Eighth Evolution of Language Conference (pp. 455-456). Singapore: World Scientific Publishing Co.

Morford, J.P. (1995). How to hunt an iguana: The gestured narratives of non-signing deaf children. In H. Bos \& T. Schermer (Eds.), Sign language research 1994: Proceedings of the Fourth European Congress on Sign Language Research (pp. 99-115). Hamburg: Signum Press.

Morford, J.P., \& Goldin-Meadow, S. (1997). From here to there and now to then: The development of displaced reference in homesign and English. Child Development, 68, 420-435.

Newport, E.L. \& Meier, R.P. (1985). The acquisition of American Sign Language. In D.I. Slobin (Ed.), The cross-linguistic study of language acquisition. Vol. 1: The data. Hillsdale: Erlbaum.

Özyürek, A., Furman, R., Kita, S., Sancar, B., \& Goldin-Meadow, S. (submitted). From gesture to homesign: The emergence of action segmentation and sequencing. 
Padden, C. (1988). Interaction of morphology and syntax in American Sign Language. New York: Garland Press.

Phillips, S.B., Goldin-Meadow, S., \& Miller, P.J. (2001). Enacting stories, seeing worlds: Similarities and differences in the cross-cultural narrative development of linguistically isolated deaf children. Human Development, 44, 311-336.

Sandler, W., Meier, I., Padden, C., \& Aronoff, M. (2005). The emergence of grammar: Systematic structure in a new language. Proceedings of the National Academy of Sciences, 102, 2661-2665.

- Senghas, A. (2003). Intergenerational influence and ontogenetic development in the emergence of spatial grammar in Nicaraguan Sign Language. Cognitive Development, 18, 511-531.

-Senghas, A., Kita, S., \& Özyürek, A. (2004). Children creating core properties of language: Evidence from an emerging Sign Language in Nicaragua. Science, 305, 1779-1782.

Singleton, J.L., Morford, J.P., \& Goldin-Meadow, S. (1993). Once is not enough: Standards of wellformedness in manual communication created over three different timespans. Language, 69, 683715.

Supalla, T. (2008). Sign language archeology: Integrating historical linguistics with fieldwork on young sign languages. In R.M. de Quadros (Ed.), Sign languages: Spinning and unraveling the past, present and future (pp. 574-583). Petrópolis: Editora Arara Azul. 